Sains Malaysiana 49(5)(2020): 1191-1200

http://dx.doi.org/10.17576/jsm-2020-4905-24

\title{
Mathematical Model of Dengue Virus with Predator-Prey Interactions
}

(Model Matematik Virus Denggi dengan Interaksi Pemangsa-Mangsa)

\author{
Sarinah Banu Mohamed SiddiK*, Farah Aini AbDUllah \& Ahmad IzANi MD. Ismail
}

ABSTRACT

In this paper, a mathematical model of dengue incorporating two sub-models that: describes the linked dynamics between predator-prey of mosquitoes at the larval stage, and describes the dengue spread between humans and adult mosquitoes, is formulated to simulate the dynamics of dengue spread. The effect of predator-prey dynamics in controlling the dengue disease at the larval stage of mosquito populations is investigated. Stability analysis of the equilibrium points are carried out. Numerical simulations results indicate that the use of predator-prey dynamics of mosquitoes at the larval stage as biological control agents for controlling the larval stage of dengue mosquito assists in combating dengue virus contagion.

Keywords: Dengue virus; endemic equilibrium; numerical simulation; predator-prey

ABSTRAK

Dalam kertas ini, satu model matematik denggi yang menggabungkan dua sub-model iaitu: menerangkan dinamik antara nyamuk pemangsa-mangsa pada peringkat jejentik dan menerangkan penyebaran denggi antara manusia dan nyamuk dewasa, diformulasikan untuk mensimulasi dinamik penyebaran denggi. Kesan dinamik pemangsa-mangsa untuk mengawal penyakit denggi pada peringkat jejentik populasi nyamuk diselidik. Analisis kestabilan titik kesimbangan dijalankan. Simulasi berangka menunjukkan bahawa penggunaan dinamik pemangsa-mangsa nyamuk pada peringkat jejentik sebagai agen kawalan biologi untuk mengawal tahap jejentik nyamuk denggi membantu dalam memerangi penularan virus denggi.

Kata kunci: Keseimbangan endemik; pemangsa-mangsa; simulasi berangka; virus denggi

\section{INTRODUCTION}

Dengue is a disease that is endemic in over a hundred countries (WHO 2016). Since the 1970s, dengue fever has spread throughout the Southeast Asia and as of 2010 about 60 million people were infected with the virus (Wen et al. 2016). Dengue virus is transmitted to humans through a type of mosquito known as Aedes aegypti (Zaini et al. 2019). Aedes aegypti is responsible for most of the global dengue diffusion although some other species such as Aedes albopictus is also involved (Nuraini et al. 2009; Ong 2016). Infection with dengue virus may cause either dengue fever (DF), dengue hemorrhagic fever (DHF) or dengue shock syndrome (DSS) (Derouich \& Boutayeb 2006). The DHF and the DSS are the severest forms of dengue disease which may lead to fatality greater than 20\% (WHO 2016). Individuals infected by one serotype of the virus will become immune to that serotype. Nevertheless, subsequent infection with any of the other three serotypes makes the individual prone to DHF and DSS. The DF is described by a sudden fever and intense headaches and persists for three to seven days. On the other hand, the DHF or DSS is characterized by a sudden fever, nausea, vomiting and fainting due to low blood pressure. It takes between two to three days to recover and may lead to death (Derouich \& Boutayeb 2006). Thus investigating possible procedures for controlling the spread of dengue is important. The best way to manage dengue occurrence is to focus on prevention - keeping the mosquito population below the spread threshold (Esteva \& Vargas 1998).

Many mathematical models of dengue transmission dynamics have been developed. Bailey (1975) introduced the first basic mathematical model of dengue. Amathematical model for dengue with variable humans and mosquitoes consisting of susceptible-infected-recovered model for humans and susceptible-infected for the mosquitoes was formulated. Later, Esteva and Vargas (1998) extended the Bailey's model to establish the global stability of the endemic equilibrium to the model. They concluded that the disease-free equilibrium is stable whenever a basic reproduction number is smaller than unity. This model was used to study the effectiveness of insecticide dispersion. Derouich and Boutayeb (2006) formulated a mathematical model for dengue fever with the aim of investigating the effect of immunization. They also discussed the possibility of a partial vaccination to control a second epidemic and the evolution of dengue to DHF. Yang and Ferreira (2008) 
extended the basic model of Bailey (1975) by testing different vector-control strategies. Mosquito maturation stages and a variable recruitment rates were taken into account. They introduced an efficiency index, defined as the reduction factor of the adult vector population after vector control, to evaluate the impact of control measures. It was found that although all the control policies were efficient to reduce vector population size with efficiency index up to $80 \%$, this trend was not observed in the host population. For the most population, the reduction of dengue cases was less than 40\%. Erikson et al. (2010a) then extended the model of Derouich and Boutayeb (2006) by adding the exposed class in human population. Other extensions of the Bailey dengue model includes the model developed by Erikson et al. (2010b) which took into account age structure in the human population. Pandey et al. (2013) developed two mathematical models of dengue transmission. In one of the models, the mosquitoes are explicitly tracked (vector-host dengue model) and the other was without explicit mosquito populations (SIR model). They studied the impact of modeling assumptions on dengue dynamics in Thailand by fitting the DHF data to a simple vector host and SIR models by using Bayesian Markov chain Monte Carlo estimation. They showed that the model selection of SIR model was superior to the vector-host model for the DHF data from Thailand. To the best of our knowledge, the aforementioned studies did not assess the impact of any control strategies to control the dengue epidemic.

Biological approaches are also being considered as an alternative method to control mosquito populations (Nyamah et al. 2011). For example, the use of Toxorhynchites splendens (Tx. splendens) species mosquitoes predatory in controlling Aedes aegypti at the larval stage of mosquito populations (Huang et al. 2017). Moreover, the use of larvivorous Tx. splendens mosquitoes is an environment-friendly method to control the mosquito larvae (Nyamah et al. 2011; Steffan \& Evenhuis 1981). Besides, Aedes aegypti prey is associated with the presence of Tx. splendens predator because both species share the same breeding habitat. Tx. splendens predator larvae frequently coexist together with other species of mosquito larvae in the same habitat (Zuharah et al. 2015). Ali et al. (2015) developed a mathematical model of Tx. splendens mosquitoes as a biological control strategy to reduce dengue disease propagation, modified from the model of Rodrigues et al. (2012). They take account the aquatic stage of Aedes aegypti mosquitoes but did not observe Tx. splendens mosquitoes as biological control strategy at the aquatic stage. Moreover, the link between these two species of mosquitoes was not mentioned in the model. They did not consider the larval stage of both mosquitoes species.

Moore et al. (2010) derived the first mathematical model that linked the predator-prey and host-pathogen theory. The work aimed at investigating the indirect consequence of predators on vector-pathogen dynamics.
The model was used to establish whether the predation can check pathogen perseverance or change the stability of host-pathogen dynamics. The study showed that the absence of predation leads to proportional increment of pathogen pervasiveness in the host with vector productiveness. The predator can raise the host number indirectly by reducing or eradicating infectivity in the host population. However, only one control strategy was considered in this model.

Lou and Zhao (2011) presented a mathematical malaria model which describes the linked dynamics between the host-vector and the predator-prey interactions. The model modified the work of Moore et al. (2010) by focusing on the impact of the predator-larval mosquito relations on the transmission of mosquito-borne pathogens. The study evaluated the possible impacts of the biological control strategy on the spread of the disease. They concluded that introducing carnivorous fish as a biological control strategy can have important consequences for the disease dynamics. The introduction of larvivorous fish also has consequences for malaria dynamics and indicates that strong predators are required on larval mosquitoes. Nevertheless, the model did not consider the susceptible human and the recovered human and only one control strategy was considered in this model.

Ghosh et al. (2013) derived a nonlinear mathematical model for malaria which studied the introduction of predatory fish as a biological control agent by considering both human and mosquitoes populations variable. They modified the model of Lou and Zhao (2011) by incorporating all possible breeding sites of mosquitoes. They concluded that the introduced predatory fish has an effect on the spread of the disease. It should be noted the model did not consider the recovered human population since human are either recovered or get immunity and only one control strategy was used in this model.

Most of the current activities to develop biological control strategies require several challenges, thus, making a prediction of the biological predator intervention uncertain. Based on this, the model considered in this study offers some extensions to the dengue transmission model in Ali et al. (2015), and Pandey et al. (2013) which describes the linked dynamics between the predatorprey interactions, humans and adult mosquitoes interaction. The predator-prey dynamic of mosquitoes at the larval stage involve the use of larvivorous $T x$. splendens mosquitoes as biological control agent for controlling the larval stage of dengue mosquito (Aedes aegypti). Moreover, the model will examine its impact in reducing the spread of dengue. The model involves the interactions between human and mosquito populations, and mathematically written as a system of ordinary differential equations.

Our paper is structured as follows: in the next section, a mathematical model is developed to simulate the dynamics of the dengue disease spread. Equilibrium 
state and stability are discussed subsequently. After that, the model is investigated numerically. Finally, we present the conclusion in the last section.

\section{METHODS}

\section{FORMULATION OF THE MODEL}

The works of Ali et al. (2015) and Pandey et al. (2013) are extended by incorporating the use of predatorprey dynamics of mosquitoes at the larval stage. We develop a mathematical model that integrates two sub interactions: predator-prey (larvivorous Tx. splendens and larvae Aedes aegypti mosquitoes) and human-adult mosquitoes. We seek to examine the indirect effect of predators via a mosquito since current models of disease dynamics have yet to consider the potential role of predators in regulating mosquito populations (Moore 2010). Figure 1 shows a schematic diagram of the model.

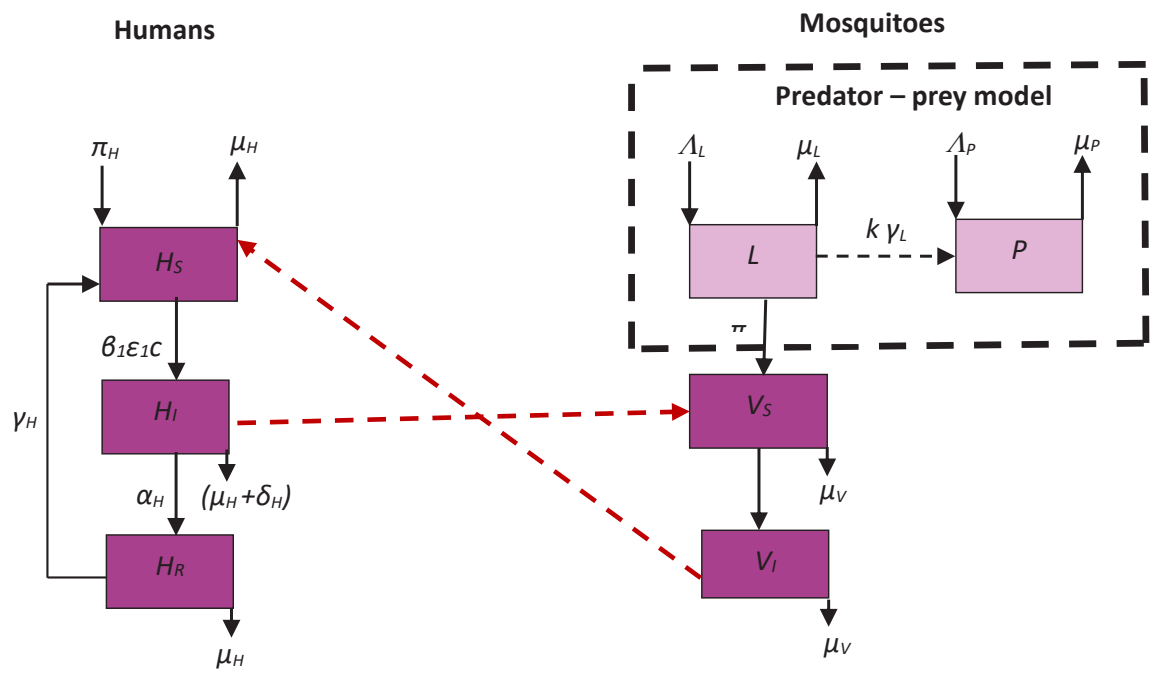

FIGURE 1. Schematic diagram of the model

\section{MODEL STRUCTURE}

The total human population at time $t$, denoted by $H(t)$, is divided into susceptible human $H_{s}(t)$, infected human $H_{I}(t)$ and recovered human $H_{R}(t)$ (Pandey et al. 2013). Hence,

$$
H=H_{S}+H_{I}+H_{R}
$$

The Aedes aegypti mosquito population is split into the larval stage of Aedes aegypti mosquitoes $L$, the larval stage of predatory mosquitoes (Tx. splendens mosquitoes) $P$ and the total adult Aedes aegypti mosquito stage at a time $t$, denoted by $V(t)$, which in turn is split into susceptible mosquitoes $V_{s}(t)$ and infected mosquitoes $V_{I}(t)$. Thus,

$$
V=V_{S}+V_{I}
$$

\section{HUMAN POPULATIONS}

The susceptible humans are increased via recruitment of human (by birth or immigration) into the population at a constant rate $\pi_{H}$. They are reduced once the susceptible human acquires the disease after interacting with the infected Aedes aegypti mosquito at a rate $\beta_{1} \varepsilon_{1} c$, where $\beta_{1}$ is the transmission probability per bite and $\varepsilon_{1}$ is the biting rate of mosquitoes, $c$ is the contact rate of mosquito per human per unit time. The recovered human turn out to be susceptible again at a rate $\gamma_{H}$. The susceptible human experiences natural death at a rate $\mu_{H}$ (Ali et al. 2015; Pandey et al. 2013). This gives

$$
\frac{d H_{S}}{d t}=\pi_{H}+\gamma_{H} H_{R}-\beta_{1} \varepsilon_{1} c H_{S} V_{I}-\mu_{H} H_{S} .
$$

Infected humans are generated through infection of susceptible humans following an incubation period of 4-10 days (WHO 2016). They acquire immunity at a rate $\alpha_{H}$, suffer a disease-induced death at a rate $\delta_{H}$ and natural death at a rate $\mu_{H}$ (Ali et al. 2015; Pandey et al. 2013). Thus,

$$
\frac{d H_{I}}{d t}=\beta_{1} \varepsilon_{1} c H_{S} V_{I}-\left(\alpha_{H}+\delta_{H}+\mu_{H}\right) H_{I} .
$$


Infected human evolves to the recovered class after acquiring immunity at a rate $\alpha_{H}$. The recovered human population losses immunity at a rate $\gamma_{H}$ and suffers a natural death at a rate $\mu_{H}$ (Ali et al. 2015; Pandey et al. 2013). Hence,

$$
\frac{d H_{R}}{d t}=\alpha_{H} H_{I}-\left(\gamma_{H}+\mu_{H}\right) H_{R} .
$$

\section{LARVA STAGE OF PREDATORY MOSQUITOES}

The main contribution of this paper is where the dengue model is extended to the larval stage of predatory mosquitoes. The predatory mosquito here is $T x$. splendens mosquitoes. It is assumed that the larval stage of predatory mosquitoes $P$ is generated by egg laying rate of the mosquitoes at a rate $\Lambda_{P}$. Predatory mosquito larval stage suffers a natural death at a rate $\mu_{P}$. The larva matures at a rate $\pi_{P}$ and leaves the larval stage to adult mosquito with the assumption that $k$ is the tropical convention efficiency. The adult Tx. splendens mosquitoes does not consume blood while feeding on sugar rich materials such as fruit and nectar (Benelli et al. 2016). The predation of the larvae by the predatory mosquitoes is assumed to take a linear response form with a constant rate $\gamma_{L}$ (Ghosh et al. 2013). This gives

$$
\frac{d P}{d t}=\Lambda_{P}+k \gamma_{L} L P-\left(\pi_{P}+\mu_{P}\right) P
$$

\section{PREY MOSQUITOES POPULATIONS}

The larval stage of Aedes aegypti mosquitoes $L$ are generated by egg laying rate of the mosquitoes at a rate $\Lambda_{L}$. Other mosquitoes larvae suffer death due to larvivorous predatory $T x$. splendens larvae feed on the mosquito larvae at a rate $\gamma_{L} P$ and a natural death of larvae itself at a rate $\mu_{L}$. Then, the larvae matures at a rate $\pi_{V}$, leaving the larval stage to adult mosquitoes (Ghosh et al. 2013). Thus,

$$
\frac{d L}{d t}=\Lambda_{L}-\left(\pi_{V}+\gamma_{L} P+\mu_{L}\right) L
$$

Susceptible mosquitoes are generated via recruitment of Aedes aegypti mosquitoes (birth or immigration) at a constant rate $\pi_{V}$. They acquire the infection after the interaction with humans, at a rate $\beta_{2} \varepsilon_{2} c$, where $\beta_{2}$ is the probability of Aedes aegypti mosquitoes getting infected through infected humans, $\varepsilon_{2}$ is the biting rate of mosquitoes and $C$ is the contact rate of mosquito per human per unit time. It experiences a natural death at a rate $\mu_{V}$ (Ali et al. 2015; Pandey et al. 2013). Therefore,

$$
\frac{d V_{S}}{d t}=\pi_{V} L-\beta_{2} \varepsilon_{2} c V_{S} H_{I}-\mu_{V} V_{S} .
$$

From the above assumptions and formulations together with the schematic diagram in Figure 1, the resulting system of non-linear differential equations for the dengue model is obtained:

$$
\left.\begin{array}{l}
\frac{d H_{S}}{d t}=\pi_{H}+\gamma_{H} H_{R}-\beta_{1} \varepsilon_{1} c H_{S} V_{I}-\mu_{H} H_{S} \\
\frac{d H_{I}}{d t}=\beta_{1} \varepsilon_{1} c H_{S} V_{I}-\left(\alpha_{H}+\delta_{H}+\mu_{H}\right) H_{I} \\
\frac{d H_{R}}{d t}=\alpha_{H} H_{I}-\left(\gamma_{H}+\mu_{H}\right) H_{R} \\
\frac{d P}{d t}=\Lambda_{P}+k \gamma_{L} L P-\left(\pi_{P}+\mu_{P}\right) P \\
\frac{d L}{d t}=\Lambda_{L}-\left(\gamma_{L} P+\pi_{V}+\mu_{L}\right) L \\
\frac{d V_{S}}{d t}=\pi_{V} L-\beta_{2} \varepsilon_{2} c V_{S} H_{I}-\mu_{V} V_{S} \\
\frac{d V_{I}}{d t}=\beta_{2} \varepsilon_{2} c V_{S} H_{I}-\mu_{V} V_{I}
\end{array}\right\}
$$

The model (9) describes the interaction between susceptible, infected and recovered human population in $\left(9_{1}\right)-\left(9_{3}\right)$ with change in time. Similarly, the susceptible and infected mosquito populations interact in $\left(9_{6}\right)-\left(9_{7}\right)$ with change in time.

\section{MODEL ANALYSIS}

\section{INVARIANT REGION}

Let $\left(H_{S}, H_{I}, H_{R}, P, L, V_{S}, V_{I}\right) \in \mathbf{R}_{+}^{7}$ be any solution of the system with nonnegative initial conditions that is,

$$
\frac{d H}{d t} \leq \pi_{H}-\mu_{H} H
$$

Thus, from the standard comparison theorem by Cooke and Van Den Driessche (1996), it is clear that $0 \leq H \leq \frac{\pi_{H}}{\mu_{H}}$, such as written in a simplified form. Thus,

$$
\pi_{H}-\mu_{H} H \geq K e^{-\mu_{H} t} \text { where } K \text { is a constant. }
$$

Hence, all possible solutions of the human population of the model (9) are in the region

$$
\Omega_{H}=\left\{\left(H_{S}, H_{I}, H_{R}\right) \in \mathbf{R}_{+}^{3}: H \leq \frac{\pi_{H}}{\mu_{H}}\right\}
$$

Similarly, all the possible solutions of the mosquito population of the model (9) are in the same region with human population as follow,

$$
\begin{gathered}
\Omega_{L}=\left\{(P, L) \in \mathbf{R}_{+}^{2}: P \leq \frac{\Lambda_{P}}{\pi_{P}+\mu_{P}}, L \leq \frac{\Lambda_{L}}{\pi_{V}+\mu_{L}}\right\}, \\
\Omega_{V}=\left\{\left(V_{S}, V_{I}\right) \in \mathbf{R}_{+}^{2}: V \leq \frac{\pi_{V} \Lambda_{L}}{\mu_{V}\left(\pi_{V}+\mu_{L}\right)}\right\} .
\end{gathered}
$$

Therefore, the feasible set of the model (9) is given by

$$
\Omega=\left\{\begin{array}{c}
\left(H_{S}, H_{I}, H_{R}, L, P, V_{S}, V_{I}\right) \in \mathbf{R}_{+}^{7}: H_{S}, H_{I}, H_{R}, L, P, V_{S}, V_{I} \geq 0 ; \\
H \leq \frac{\pi_{H}}{\mu_{H}}, P \leq \frac{\Lambda_{P}}{\pi_{P}+\mu_{P}}, L \leq \frac{\Lambda_{L}}{\pi_{V}+\mu_{L}}, V \leq \frac{\pi_{V} \Lambda_{L}}{\mu_{V}\left(\pi_{V}+\mu_{L}\right)}
\end{array}\right\}
$$


The positively invariant is induced by the model (9) and hence, the non-negative properties have been preserved for the total size of the population. Furthermore, in this domain, it is sufficient to consider the dynamics of the flow generated by the model (9). The investigation of invariant region includes both humans and mosquitoes population.

\section{POSITIVITY OF SOLUTION}

Since the model (9) monitors human and mosquito populations, it is therefore important that all state variables involved are non-negative for all time and are bounded in $\mathbf{R}_{+}^{7}$, because the total populations of both human and mosquito are non-negative. Let the initial data be $\left\{H_{S}(0), H_{I}(0), H_{R}(0), P(0), L(0), V_{S}(0), V_{I}(0) \geq 0\right\}$ $\in \Omega$,

Then, the solution set $\left\{H_{S}, H_{r}, H_{R}, P, L, V_{S}, V_{l}\right\}(t)$ of the model (9) is positive for all $t>0$. Based on the model (9) the first equation yields,

$$
\begin{aligned}
& \frac{d H_{S}}{d t}=\pi_{H}+\gamma_{H} H_{R}-\left(\lambda_{1}+\mu_{H}\right) H_{S} \geq-\left(\lambda_{1}+\mu_{H}\right) H_{S} \\
& \frac{d H_{S}}{d t} \geq-\left(\lambda_{1}+\mu_{H}\right) H_{S} \\
& \int \frac{d H_{S}}{H_{S}} \geq-\int\left(\lambda_{1}+\mu_{H}\right) d t \\
& H_{S}(t) \geq H_{S}(0) e^{-\left(\lambda_{1}+\mu_{H}\right) t} \\
& H_{S}(t) \geq 0 .
\end{aligned}
$$

As $t \rightarrow \infty, H_{S}(t)>0$, from the model (9) the seventh equation gives

$$
\left.\begin{array}{l}
\frac{d V_{I}}{d t}=-\lambda_{2} V_{S}-\mu_{V} V_{I} \geq-\mu_{V} V_{I} \\
\frac{d V_{I}}{d t} \geq-\mu_{V} V_{I} \\
\int \frac{d V_{I}}{V_{I}} \geq-\int \mu_{V} V_{I} d t \\
V_{I}(t) \geq V_{I}(0) e^{-\mu_{V} V_{I} t} \\
V_{I}(t) \geq 0 .
\end{array}\right\}
$$

As $t \rightarrow \infty, V_{I}(t)>0$. Similarly, it can be shown that $H_{I}, H_{R}, L, P, V_{S}$ are greater than zero for all time, $t>0$.

\section{EQUILIBRIUM POINTS AND STABILITY}

In this section, the model (9) is analyzed to identify the equilibrium points of the system and their stability properties. To find the equilibrium points of the model
(9), the model is set to zero on the right hand side to obtain the following system of equations;

$$
\left.\begin{array}{l}
\pi_{H}+\gamma_{H} H_{R}-\beta_{1} \varepsilon_{1} c_{1} H_{S} V_{I}-\mu_{H} H_{S}=0 \\
\beta_{1} \varepsilon_{1} c_{1} H_{S} V_{I}-\left(\delta_{H}+\alpha_{H}+\mu_{H}\right) H_{I}=0 \\
\alpha_{H} H_{I}-\left(\gamma_{H}+\mu_{H}\right) H_{R}=0 \\
\Lambda_{P}+k \gamma_{L} L P-\left(\pi_{P}+\mu_{P}\right) P=0 \\
\Lambda_{L}-\left(\gamma_{L} P+\pi_{V}+\mu_{L}\right) L=0 \\
\pi_{V} L-\beta_{2} \varepsilon_{2} c_{1} V_{S} H_{I}-\mu_{V} V_{S}=0 \\
\beta_{2} \varepsilon_{2} c_{1} V_{S} H_{I}-\mu_{V} V_{I}=0
\end{array}\right\}
$$

The model (9) exhibits two types of equilibrium which are disease-free equilibrium (DFE) and disease-free equilibrium state $E_{0}$ in the absence of infection by the disease (dengue). The DFE are equilibrium-point solutions when there is no disease (dengue). Diseased compartments are classes of both human and mosquito populations that are infected with dengue in the model (9). Therefore, in the absence of infection, that is when $H_{I}, V_{I}=0$, the model (9) has a point known to be infection free equilibrium or disease-free equilibrium state $E_{0}$ as a steady state. If $H_{I}, V_{I}$ $=0$ is substituted in the model (9), the system reduces to $\pi_{H}-\mu_{H} H_{S}=0$ implying that $H_{S}^{*}=\frac{\pi_{H}}{\mu_{H}}$ for human population and for mosquito population, the system reduces to $\pi_{V} L$ $\mu_{V} V_{S}=0$, implying that $V_{S}^{*}=\frac{\pi_{V} \Lambda_{L}}{\mu_{V}\left(\pi_{V}+\mu_{L}\right)}$. Consequently, the DFE point of the model (9) is attained by putting,

$$
\frac{d H_{S}}{d t}=\frac{d H_{I}}{d t}=\frac{d H_{R}}{d t}=\frac{d P}{d t}=\frac{d L}{d t}=\frac{d V_{S}}{d t}=\frac{d V_{I}}{d t}=0 .
$$

Thus, from (19) the infection free equilibrium point is given by,

$$
\begin{aligned}
E_{0} & =\left(H_{S}^{*}, H_{I}^{*}, H_{R}^{*}, P^{*}, L^{*}, V_{S}^{*}, V_{I}^{*}\right), \\
& =\left(\frac{\pi_{H}}{\mu_{H}}, 0,0, \frac{\Lambda_{P}}{\pi_{P}+\mu_{P}}, \frac{\Lambda_{L}}{\pi_{V}+\mu_{L}}, \frac{\pi_{V} \Lambda_{L}}{\mu_{V}\left(\pi_{V}+\mu_{L}\right)}, 0\right) .
\end{aligned}
$$

This represents the state where there is no infectivity in a community and it is known as the disease free equilibrium point.

\section{BASIC REPRODUCTION NUMBER, $\mathfrak{R}_{0}$}

In a fully susceptible population, the basic reproduction number is the number of new cases that one infected individual will produce for the duration of its period of infectiousness. As $\mathfrak{R}_{0}<1$, each infected individual typically leads to less than one diseased individual and 
hence the infection dies out. If $\mathfrak{R}_{0}<1$, each infected individual will produce more than one new infected individual. Thus, the infection overruns the population. Therefore, it is a measure of the severity of the epidemic. Next Generation Operator is then used to establish the linear stability of the disease (Diekmann et al. 1990). Since the concern is with the populations that spread the infection (Heffernan et al. 2005), we thus, considers only the infected compartments $H_{P}, V_{I}$ of the model (9). In order to compute the basic reproduction number $\mathfrak{R}_{0}$, we have

$$
\left.\begin{array}{l}
\frac{d H_{I}}{d t}=\lambda_{1} H_{S}-\left(\delta_{H}+\mu_{H}+\alpha_{H}\right) H_{I} \\
\frac{d V_{I}}{d t}=\lambda_{2} V_{S}-\mu_{V} V_{I}
\end{array}\right\}
$$

Then, the matrices $F_{i}$ and $V_{i}$ are the rates of appearance of new infection in the compartment $i$ and the removal of persons/mosquitoes into and out of compartment $i$ by all other means respectively. Hence, they are obtained as follows,

$$
F_{i}=\left[\begin{array}{c}
\lambda_{1} H_{S} \\
\lambda_{2} V_{S}
\end{array}\right]
$$

and

$$
V_{i}=\left[\begin{array}{c}
\left(\delta_{H}+\mu_{H}+\alpha_{H}\right) H_{I} \\
\mu_{V} V_{I}
\end{array}\right] .
$$

Thus, to obtain the appearance of new infection $\left(F_{i}\right)$ and the removal of individuals in and out of the compartment $i$ and $V_{i}$ from model (9), two infected classes need to be considered; one class of humans and the other one from Aedes aegypti mosquito populations. Partial derivatives of $F_{i}$ and $V_{i}$ with respect to the infected classes, $H_{I}, V_{I}$ are given respectively, as

$$
\begin{gathered}
F=\left[\begin{array}{cc}
0 & \beta_{1} \varepsilon_{1} c_{1} H_{S} \\
\beta_{2} \varepsilon_{2} c_{1} V_{S} & 0
\end{array}\right], \\
V=\left[\begin{array}{cc}
\delta_{H}+\mu_{H}+\alpha_{H} & 0 \\
0 & \mu_{V}
\end{array}\right] .
\end{gathered}
$$

Evaluating $F$ at DFE, $E_{0}$ yield

$$
F=\left[\begin{array}{cc}
0 & \beta_{1} \varepsilon_{1} c_{1} \frac{\pi_{H}}{\mu_{H}} \\
\beta_{2} \varepsilon_{2} c_{1} \frac{\pi_{V} \Lambda_{L}}{\mu_{V}\left(\pi_{V}+\mu_{L}\right)} & 0
\end{array}\right],
$$

and

$$
V^{-1}=\left[\begin{array}{cc}
\frac{1}{\delta_{H}+\mu_{H}+\alpha_{H}} & 0 \\
0 & \frac{1}{\mu_{V}}
\end{array}\right] .
$$

The two matrices $F$ and $V^{-1}$ are conducted using Maple-17 to obtain the basic reproduction numbers and it is given by,

$$
\mathfrak{R}_{0}=\rho\left(F V^{-1}\right)=\frac{\beta_{1} \varepsilon_{1} c_{1}^{2} \pi_{H} \beta_{2} \varepsilon_{2} \pi_{V} \Lambda_{L}}{\mu_{H}\left(\pi_{H}+\mu_{L}\right)\left(\delta_{H}+\mu_{H}+\alpha_{H}\right) \mu_{V}^{2}}
$$

Hence, The DFE of the model (9) is given by $E_{0}$ which is locally asymptotically stable. This means the disease will die out in the community (stable) if $\mathfrak{R}_{0}<1$ and unstable if $\mathfrak{R}_{0}>1$.

\section{NUMERICAL SIMULATIONS}

In order to illustrate the behavior of both mosquito and human population interact with and without control of predatory mosquitoes, numerous simulations were conducted by applying the set of parameters values depicted in Table 1. All the simulations and graph were obtained using MATLAB software.

TABLE 1. Description of parameters for model (9)

\begin{tabular}{cccc}
\hline Parameter & Description & Est. value & References \\
\hline$\pi_{H}$ & Recruitment rate of human & 60 & Andraud et al. (2012) \\
$\pi_{V}$ & Recruitment rate of Aedes aegypti mosquitoes & 3000 & Andraud et al.(2012) \\
$\mu_{H}$ & Natural death of human & 0.0000457 & Al-Sulami et al. (2014) \\
$\delta_{H}$ & Disease-induced death of human & 0.05 & Hove-Musekwa et al. (2008)
\end{tabular}




\begin{tabular}{|c|c|c|c|}
\hline$\gamma_{H}$ & Rate of loss of human immunity & 0.02877 & Menach et al. (2005) \\
\hline$\beta_{1}$ & Probability of human getting infected & 0.75 & Al-Sulami et al. (2014) \\
\hline$\varepsilon_{1}$ & Biting rate of human & 1 & Derouich and Boutayeb (2006) \\
\hline$c$ & Contact rate of Aedes aegypti mosquito per human per unit & 0.75 & Derouich and Boutayeb (2006) \\
\hline$\beta_{2}$ & Probability of Aedes aegypti mosquitoes getting infected & 1 & Al-Sulami et al. (2014) \\
\hline$\varepsilon_{2}$ & Biting rate of Aedes aegypti mosquitoes & 0.5 & Al-Sulami et al. (2014) \\
\hline$\alpha_{H}$ & Recovery rate of human & 0.1428 & Al-Sulami et al. (2014) \\
\hline$\mu_{V}$ & Natural death of Aedes aegypti mosquitoes & 0.25 & Al-Sulami et al. (2014) \\
\hline$\Lambda_{P}$ & Egg laying rate of predatory mosquitoes & 50 & Ghosh et al. (2013) \\
\hline$\Lambda_{L}$ & Egg laying rate of Aedes aegypti mosquitoes & 10 & Ghosh et al. (2013) \\
\hline$k$ & Tropical convention efficiency & 0.1 & Ghosh et al. (2013) \\
\hline$\gamma_{L}$ & Predation of larva stage by predatory mosquitoes & 0.1 & Ghosh et al. (2013) \\
\hline$\pi_{P}$ & Larva stage mature of predatory mosquitoes & 0.0625 & Ghosh et al. (2013) \\
\hline$\mu_{P}$ & Natural death of predatory mosquitoes & 0.36 & Ghosh et al. (2013) \\
\hline$\mu_{L}$ & Natural death of Aedes aegypti larva & 0.05 & Ghosh et al. (2013) \\
\hline
\end{tabular}

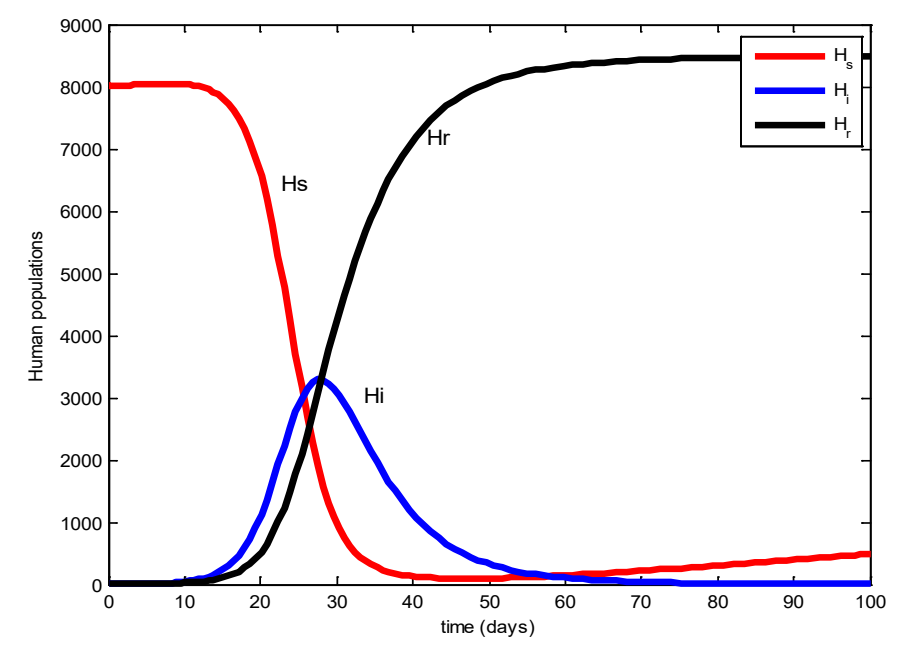

FIGURE 2. The effect of interaction of human populations without predatory mosquitoes with $H_{S}=8000, H_{I}$

$$
=0 \text { and } H_{R}=0
$$




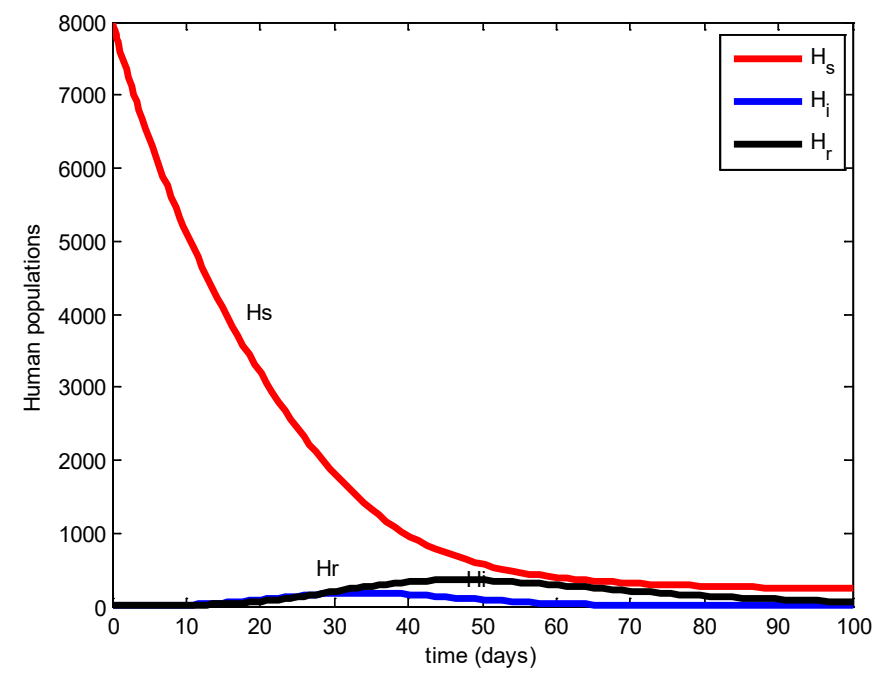

FIGURE 3. The effect of interaction of human populations with predatory mosquitoes with $H_{S}=8000, H_{I}=$ 0 and $H_{R}=0$

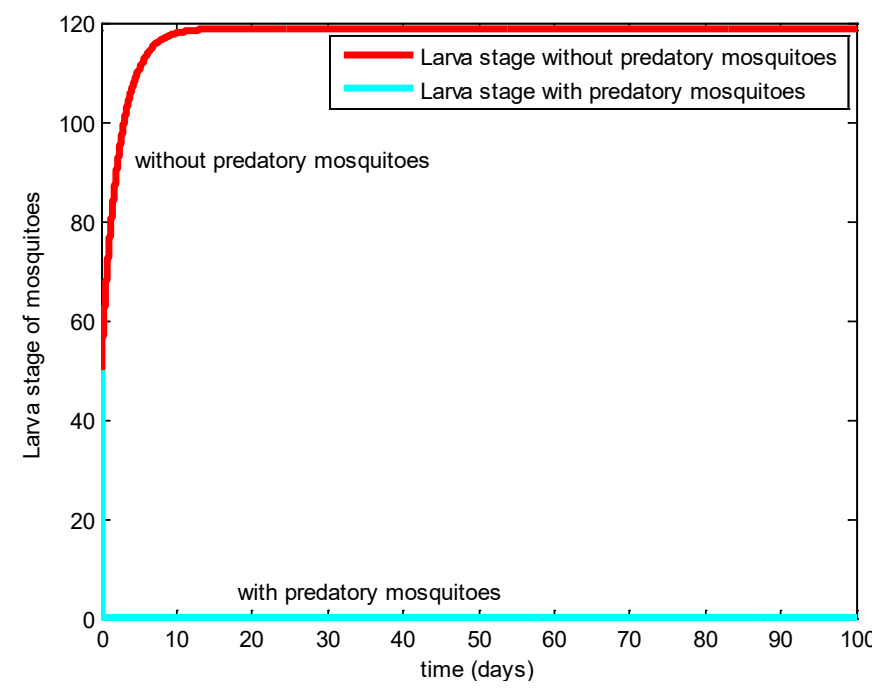

FIGURE 4. . The effect of interaction on larva mosquitoes with and without predatory mosquitoes with $L=50$ and $P=50$

The graph in Figure 2 indicates that the susceptible population is decreasing where every susceptible person is being infected by day 31 . The line for a less infectious disease would slope more gently to the right while the infected population is increasing rapidly up to a maximum of 3400 peoples by the day of 34 , and then falls more slowly until the day of 60 . The recovered population increased continuously to the day of 60 . This is because there is no control strategy (predatory mosquitoes) to control the spread of the virus. The graphs in Figure 3 indicate the typical behavior of human populations with the control of predatory mosquitoes. It has been shown that in the presence of control of predatory mosquitoes, the number of human decreases between the 50th and 60th day. The graph in Figure 4 shows that predatory mosquitoes can reduce the Aedes aegypti mosquitoes at the larval stage 
since the egg laying rate is 50 for predatory mosquitoes and 10 for prey.

\section{CONCLUSION}

Biocontrol strategies for mosquito populations are needed to help reducing the use of insecticides that are currently used for mosquito control. Despite significant improvement to the existing methods so far, larger scale trials are needed to determine the effective method of mosquito biocontrol. In view of this finding has shown that the use of predator-prey dynamic of mosquitoes at the larval stage (larvivorous $T x$. splendens larvae) can be a potential biological control agent for controlling the larval stage of dengue mosquito (Aedes aegypti) and thus in controlling the dengue virus.

\section{ACKNOWLEDGEMENTS}

We acknowledge financial support from Fundamental Research Grant Scheme, 203/PMATHS/6711570.

\section{REFERENCES}

Ali, T.M., Kamil, A.A. \& Karim, M.F.A. 2015. Deterministic mathematical model of dengue disease spread. Far East Journal of Mathematical Sciences 96(4): 419-436.

Al-Sulami, H., El-Shahed, M., Nieto, J.J. \& Shammakh, W. 2014. On fractional order dengue epidemic model. Hindawi Publishing Corporation 2014: 456537.

Andraud, M., Hens, N., Marais, C. \& Beutels, P. 2012. Dynamic epidemiological models for dengue transmission: A systematic review of structural. PLoS Comput. Biol. 7(11): 332-346.

Bailey, N.T.J. 1975. The Mathematical Theory of Infectious Diseases and Its Applications. London: Griffin.

Benelli, G., Jeffries, C.L. \& Walker, T. 2016. Biological control of mosquito vectors: Past, present and future. Insects 7(4): e52.

Cooke, K.L. \& Van Den Driessche, P. 1996. Analysis of an SEIRS epidemic model with two delays. Journal of Mathematical Biology 35(2): 240-260.

Derouich, M. \& Boutayeb, A. 2006. Dengue fever: Mathematical modelling and computer simulation. Applied Mathematics and Computation 177(2): 528-544.

Diekmann, O., Heesterbeek, J. \& Metz, J.A. 1990. On the definition and the computation of the basic reproduction ratio $\mathfrak{R}_{0}$ in models for infectious diseases in heterogeneous populations. Journal of Mathematical Biology 28(4): 365382.

Erikson, R.A., Presley, S.M., Allen, L.J.S., Long, K.R. \& Cox, S.B. 2011a. A stage-structured, Aedes albopictus population model. Ecological Modelling 221(9): 1273-1282.

Erikson, R.A., Presley, S.M., Allen, L.J.S., Long, K.R. \& Cox, S.B. 2011b. A dengue model with a dynamic Aedes albopictus vector population. Ecological Modelling 221(24): 2899-2908.

Esteva, L. \& Vargas, C. 1998. Analysis of a dengue disease transmission model. Mathematical Biosciences 150(2): $131-151$
Ghosh, M., Lashari, A.A. \& Li, X.Z. 2013. Biological control of malaria: A mathematical model. Applied Mathematics and Computation 219(15): 7923-7939.

Heffernan, J.M., Smith, R.J. \& Wahl, L.M. 2005. Perspectives on the basic reproductive ratio. Journal of the Royal Society Interface 2(4): 281-293.

Huang, Y.J.S., Stephens, H. \& Vanlandingham, D.L. 2017. Biological control strategies for mosquito vectors of arboviruses. Insect 8(1): 21-28.

Hove-Musekwa, S.D. 2008. Determining effective spraying periods to control malaria via indoor residual spraying in Sub-Saharan Africa. Journal of Applied Mathematics and Decision Sciences 2008: 745463.

Lou, Y. \& Zhao, X.Q. 2011. Modelling malaria control by introduction of larvivorous fish. Bulletin of Mathematical Biology 73(10): 2384-2407.

Menach, A.L., McKenzie, F.E., Flahault, A. \& Smith, D.L. 2005. The unexpected importance of mosquitoes oviposition behavior for malaria: Non-productive larval habitats can be sources for malaria transmission. Malaria Journal 4(1): e23.

Moore, S.M., Borer, E.T. \& Hosseini, P.R. 2010. Predators indirectly control vector borne disease: Linking predatorprey and host-pathogen models. Journal of the Royal Society Interface 7(42): 161-176.

Nuraini, N., Tasman, H., Soewono, E. \& Sidarto, K.A. 2009. A with-in host dengue infection model with immune response. Mathematical and Computer Modelling 49(5-6): 1148-1155.

Nyamah, M.A., Sulaiman, S. \& Omar, B. 2011. Field observation on the efficacy of Toxorhynchites splendens (wiedemann) as a biocontrol agent against Aedes albopictus (skuse) larvae in a cemetery. Trop. Biomed. 28(2): 312-319.

Ong, S.Q. 2016. Dengue vector control in Malaysia: A review for current and alternative strategies. Sains Malaysiana 45(5): 777-785.

Pandey, A., Mubayi, A. \& Medlock, J. 2013. Comparing vector-host and SIR models for dengue transmission. Mathematical Biosciences 246(2): 252-259.

Rodrigues, H.S., Monteiro, M.T.T., Torres, D.F.M. \& Zinober, A. 2012. Dengue disease, basic reproduction number and control. International Journal of Computer Mathematics 89(3): 334-346.

Steffan, W.A. \& Evenhuis, N.L. 1981. Biology of Toxorhynchites Annual Review of Entomology 26: 159-181.

Wen, T.H., Tsai, C.T. \& Chin, W.C.B. 2016. Evaluating the role of disease importation in the spatiotemporal transmission of indigenous dengue outbreak. Applied Geography 76 : 137-146.

World Health Organization (WHO). 2016. Dengue Report 2016. http://www.who.int/dengue/publications/world dengue report_2016/report/en.

Yang, H.M. \& Ferreira, C.P. 2008. Assessing the effects of vector control on dengue transmission. Applied Mathematics and Computation 198: 401-413.

Zaini, Z.I.I., Othman, H., Karim, N., Rashid, N.A.A., Abas, M.B.H., Sahani, M., Hod, R. \& Nordin, S.A. 2019. Knowledge and practices regarding Aedes control amongst residents of dengue hotspot areas in Selangor: A crosssectional study. Sains Malaysiana 48(4): 841-849. 
Zuharah, W.F., Fadzly, N., Yusof, N.A. \& Dieng, H. 2015. Risky behaviors: Effects of Toxorhynchites splendens (Diptera:culicidae) predator behavior of three mosquito species. Journal of Insect Sciences 15(1): 128-134.

Sarinah Banu Mohamed Siddik*

Institute of Engineering Mathematics

Universiti Malaysia Perlis

02600 Arau, Perlis

Malaysia
Farah Aini Abdullah \& Ahmad Izani Md. Ismail School of Mathematical Sciences

Universiti Sains Malaysia

11800 USM Pulau Pinang

Malaysia

*Corresponding author; email: sarinah@unimap.edu.my

Received: 8 August 2019

Accepted: 15 January 2020 